\title{
Study on Application of Hawthorn Seed in Cultivation of Pleurotus ostreatus
}

\author{
Guohao Shi ${ }^{1}$, Shuai $\mathrm{Wu}^{2}$, Chuanhe $\mathrm{Zhu}^{1}$ \\ ${ }^{1}$ Key Laboratory of Food Processing Technology and Quality Control in Shandong Province, College of Food Science and Engineering, \\ Shandong Agricultural University, Taian 271018, China \\ ${ }^{2}$ Yantai Testing Center for Food and Drug, Yantai, 264000, China;
}

\begin{abstract}
In the paper, the cultivation of Pleurotus ostreatus using abandoned hawthorn seeds as a culture medium was investigated. The results indicated that the addition of hawthorn seeds will slow down the growth of Pleurotus ostreatus, but will increase the biological efficiency, nutrient quality and antioxidant capacity of fruiting bodies. Under the condition that hawthorn seed content is $30 \%$, the cultivated Pleurotus ostreatus fruit body has the highest biological efficiency, the strongest antioxidant capacity, and the best nutritional quality.
\end{abstract}

\section{Introduction}

China is a big country producing hawthorn. The output of hawthorn has been increasing year by year, and it has become one of the four main fruits cultivated after citrus, apple and pear. With the rapid development of hawthorn processing industry, a large amount of waste will naturally be generated, and can cause serious waste and pollute the environment. For a long time, domestic and foreign experts and scholars' research on hawthorn has been limited to its pulp processing technology, chemical composition and extraction of effective components of hawthorn leaves, and little research on hawthorn by-products [1]. Nowadays, the concept of low-carbon economy is popular, and research on the utilization of hawthorn seed waste is necessary.

Hawthorn seed is one of the main by-products of hawthorn processing. The use of hawthorn seeds will produce a lot of economic benefits. Some scholars have found that hawthorn seeds are rich in flavonoids, which are active substances useful to the human body. They have obvious functions of regulating blood lipids and health. They are a high-quality resource for the development of flavonoids [2]. Most of the substances isolated from hawthorn seeds showed a moderate degree of free radical scavenging activity in the DPPH assay, and showed significant activity in the ABTS and FRAP assays. It can be seen that hawthorn seeds can be considered as a potential new and a source of cheap antioxidants [3]. Not only that, the unique structure of hawthorn seeds also provides a good raw material basis for the preparation of activated carbon [4]. But, up to now, the utilization of hawthorn seed has not realized industrial production.

Hawthorn seeds have a huge yield, high lignification, rich carbon content, and high reutilization value [5], which is very suitable for the substrate conditions for the growth of Pleurotus ostreatus. Therefore, in order to explore the efficient utilization of hawthorn seeds, the cultivation techniques of Pleurotus ostreatus and the nutritional quality of Pleurotus ostreatus were investigated using the hawthorn seeds.

\section{Materials and methods}

\subsection{Experimental methods}

2.1.1. Experimental materials. Xia Hui No. 1: From Tai'an Academy of Agricultural Sciences; Hawthorn seeds: Hawthorn is produced in Jinan.

\subsubsection{Preparation formula of hawthorn seed culture} medium. The prepared medium (Table 1) was placed in a polyethylene cylinder bag of $44 \mathrm{~cm} \times 22 \mathrm{~cm} \times 0.04 \mathrm{~cm}$, and autoclaved at $121^{\circ} \mathrm{C}$. The activated strains were inoculated separately into the hawthorn seed medium, and then placed in a $25^{\circ} \mathrm{C}$ incubator in the dark[6].

Table 1 The formula of hawthorn seed medium

\begin{tabular}{ccccc}
\hline $\begin{array}{c}\text { Added amount of hawthorn } \\
\text { seeds }(\%)\end{array}$ & Hawthorn seeds (\%) & $\begin{array}{c}\text { Cottonseed husk } \\
(\%)\end{array}$ & $\begin{array}{c}\text { Plaster } \\
(\%)\end{array}$ & $\begin{array}{c}\text { Lime } \\
(\%)\end{array}$ \\
\hline
\end{tabular}

*Corresponding author's e-mail: chhzhu@sdau.edu.cn 


\begin{tabular}{ccccc}
\hline 0 & 0 & 98 & 1 & 1 \\
10 & 10 & 88 & 1 & 1 \\
20 & 20 & 78 & 1 & 1 \\
30 & 30 & 68 & 1 & 1 \\
40 & 40 & 58 & 1 & 1 \\
50 & 50 & 48 & 1 & 1 \\
\hline
\end{tabular}

2.1.3. Mycelium growth. The germination and length of the pleurotus formula were observed an recorded. Mycelial growth rate was gained by the methods reported by $\mathrm{Lu}$ et al [7]. The calculation formula:

Mycelial growth rate $(\mathrm{cm} / \mathrm{d})=$ medium thickness / feeding time

\subsubsection{Determination of Yield of Pleurotus ostreatus.} A total of three batches of Pleurotus ostreatus were harvested. During each batch of harvesting, the yield of each bag of Pleurotus ostreatus was calculated, and then the unit yield of each bag of Pleurotus ostreatus was calculated. Formula of Pleurotus ostreatus biological efficiency:

Biological efficiency $=$ fresh mushroom weight $/$ dry material weight $\times 100 \%[8]$.

\subsubsection{Determination of physical indexes of} Pleurotus ostreatus fruit bodies. The thickness and diameter of the cover of Pleurotus ostreatus, the length and diameter of the stipe are measured using scales, the mass of the fruit body mushrooms is measured using an electronic balance, and the volume of the fruit body mushrooms is measured using the drainage method. According to:

Fruiting body weight $=$ single mushroom mass $/$ single mushroom volume to calculate [9].

\subsection{Analysis method}

2.2.1. Determination of nutrition quality index of Pleurotus ostreatus fruit bodies. Determination of crude protein content the crude protein content of Pleurotus ostreatus fruit bodies was measured by the biuret method [10]. Reducing sugar was measured by DNS method [11]. The total sugar content of Pleurotus ostreatus fruit body was determined using the national standard GB / T 15672-2009. The ash content of Pleurotus ostreatus is determined by the national standard GB 5009.4-2016. The determination of crude fat in Pleurotus ostreatus was carried out using a fully automatic fat analyser (GB 5009.6-2016). The determination of crude fibre is based on the national standard GB 5009.10-2003 (Determination of crude fibre in plant foods). Moisture is measured refer to national standard GB 5009.3-2016.

2.2.2. Determination of antioxidant capacity in vitro. The determination of DPPH radical scavenging power is based on the method of Kwaw et al. [12]. The determination of hydroxyl radical scavenging ability is based on the method of Huang Yan et al. [13].

\subsection{Data analysis}

Excel 2010 and SPSS 21.0 were used for experimental design and data analysis, and overall analysis was performed in combination with analysis of variance. Each experiment was performed in parallel 3 times.

\section{3. results and analysis}

\subsection{Effect of Hawthorn Seed Addition on Pleurotus Ostreatus Growth and Yield}

3.1.1. Effect of Hawthorn Seed Addition on Pleurotus Ostreatus Growth. It can be seen from Table 2 that the addition of hawthorn seeds to the culture medium can shorten the bag filling time and harvest time of Pleurotus ostreatus. It can be seen that although the addition of hawthorn seeds slows down the mycelial speed, the time for mushrooming is significantly shortened. Based on the comprehensive mycelial growth rate, the full bag length and the harvest time, the growth rate of $10 \%$ hawthorn seeds treatment was the fastest, followed by $20 \%$ and $0 \%$. Compared with $10 \%$ and $20 \%$, adding $30 \%$ hawthorn seeds had no significant difference in the mycelial growth rate $(\mathrm{p}>0.05)$.

Table 2 Effects of Different Media on the Growth Rate and Cycle of Pleurotus ostreatus

\begin{tabular}{cccc}
\hline $\begin{array}{c}\text { Added amount of hawthorn } \\
\text { seeds }(\%)\end{array}$ & Mycelial growth rate & $\begin{array}{c}\text { Time required for } \\
\text { mycelium to fill the bag }\end{array}$ & Harvest time \\
\hline 0 & $0.552 \pm 0.029 \mathrm{a}$ & $19.67 \pm 1.53 \mathrm{~d}$ & $30.67 \pm 0.58 \mathrm{bc}$ \\
10 & $0.523 \pm 0.029 \mathrm{ab}$ & $21.40 \pm 0.89 \mathrm{~cd}$ & $29.67 \pm 2.08 \mathrm{c}$ \\
20 & $0.516 \pm 0.054 \mathrm{ab}$ & $22.00 \pm 1.41 \mathrm{c}$ & $30.33 \pm 0.58 \mathrm{bc}$ \\
30 & $0.486 \pm 0.027 \mathrm{~b}$ & $22.60 \pm 0.89 \mathrm{bc}$ & $32.00 \pm 2.00 \mathrm{bc}$ \\
40 & $0.424 \pm 0.026 \mathrm{c}$ & $24.60 \pm 0.55 \mathrm{~b}$ & $32.33 \pm 0.58 \mathrm{~b}$ \\
50 & $0.388 \pm 0.008 \mathrm{c}$ & $27.00 \pm 2.94 \mathrm{a}$ & $35.00 \pm 1.00 \mathrm{a}$ \\
\hline
\end{tabular}




\subsubsection{Effect of Hawthorn Seed Addition on Yield of} Pleurotus ostreatus. From Table 3, the amount of hawthorn seeds added has a great effect on the yield of Pleurotus ostreatus, and the addition of hawthorn seeds to the culture medium can significantly improve the biological efficiency of Pleurotus ostreatus. There is a significant difference in the yield of different batches of Pleurotus ostreatus in the same treatment. For all treatments, the production of Pleurotus ostreatus is concentrated in the first two tides, and the output of the third tide is small, indicating that the fruiting bodies have basically grown at the second tide.

Table 3 Effect of Different Media on the Yield of Pleurotus ostreatus

\begin{tabular}{|c|c|c|c|c|c|}
\hline $\begin{array}{c}\text { Added } \\
\text { amount of } \\
\text { hawthorn } \\
\text { seeds (\%) }\end{array}$ & $\begin{array}{l}\text { First tide } \\
\quad(\mathrm{kg})\end{array}$ & $\begin{array}{l}\text { Second tide } \\
\quad(\mathrm{kg})\end{array}$ & $\begin{array}{l}\text { Third tide } \\
\text { ( } \mathrm{kg})\end{array}$ & $\begin{array}{l}\text { Total output } \\
\qquad(\mathrm{kg})\end{array}$ & $\begin{array}{l}\text { Biological } \\
\text { efficiency } \\
(\%)\end{array}$ \\
\hline 0 & $0.212 \pm 0.008 \mathrm{~d}$ & $0.469 \pm 0.115 \mathrm{a}$ & $0.033 \pm 0.005 \mathrm{c}$ & $0.714 \pm 0.122 \mathrm{~b}$ & $64.9 \pm 12.2 \mathrm{~b}$ \\
\hline 10 & $0.251 \pm 0.007 \mathrm{bc}$ & $0.48 \pm 0.017 \mathrm{a}$ & $0.048 \pm 0.006 \mathrm{~b}$ & $0.779 \pm 0.006 \mathrm{ab}$ & $70.8 \pm 0.6 \mathrm{ab}$ \\
\hline 20 & $0.263 \pm 0.008 \mathrm{ab}$ & $0.526 \pm 0.049 \mathrm{a}$ & $0.066 \pm 0.002 \mathrm{a}$ & $0.855 \pm 0.056 \mathrm{ab}$ & $77.7 \pm 5.6 \mathrm{ab}$ \\
\hline 30 & $0.274 \pm 0.011 \mathrm{a}$ & $0.577 \pm 0.008 \mathrm{a}$ & $0.053 \pm 0.003 \mathrm{~b}$ & $0.904 \pm 0.020 \mathrm{a}$ & $82.2 \pm 2.0 \mathrm{a}$ \\
\hline 40 & $0.269 \pm 0.010 \mathrm{a}$ & $0.56 \pm 0.111 \mathrm{a}$ & $0.025 \pm 0.006 \mathrm{~cd}$ & $0.854 \pm 0.116 \mathrm{ab}$ & $77.6 \pm 11.6 \mathrm{ab}$ \\
\hline 50 & $0.242 \pm 0.006 \mathrm{c}$ & $0.543 \pm 0.039 \mathrm{a}$ & $0.017 \pm 0.006 \mathrm{~d}$ & $0.802 \pm 0.036 \mathrm{ab}$ & $72.9 \pm 3.6 \mathrm{ab}$ \\
\hline
\end{tabular}

\subsection{Effect of different amounts of hawthorn seed medium on nutrient quality of Pleurotus ostreatus}

Water content is an important indicator of edible fungi, which directly affects the freshness, tenderness and taste of edible fungi. Crude protein content is a very important indicator for the quality of Pleurotus ostreatus. Generally, the higher the crude protein content, the better the nutritional quality of Pleurotus ostreatus. The effect of the amount of hawthorn seeds on the nutritional quality of fruiting bodies is shown in Table 4. The addition of hawthorn seeds to the culture medium can increase the content of crude fiber, reducing sugar and total sugar of Pleurotus ostreatus, and reduce the water content. The addition of hawthorn seeds to the culture medium have little effect on the content of ash and crude protein.

Table 4 Effect of different media on nutritional quality of fruiting bodies

$\begin{array}{cccccccc}\text { Added } & & & & & & \\ \text { amount of } & \text { Moisture } & \text { Total sugar } & \text { Reducing sugar } & \text { Crude fat } & \text { Crude protein } & \text { Crude fiber } & \text { Ash } \\ \text { hawthorn } & (\%) & (\%) & (\%) & (\%) & (\%) & (\%) & (\%) \\ \text { seeds }(\%) & & & & & \end{array}$

\begin{tabular}{|c|c|c|c|c|c|c|c|}
\hline 0 & $89.20 \pm 0.15 \mathrm{a}$ & $\begin{array}{c}34.67 \pm 1.44 \\
\mathrm{f}\end{array}$ & $\begin{array}{c}5.82 \pm 2.57 \\
\mathrm{c}\end{array}$ & $\begin{array}{c}2.23 \pm 0.28 \\
\mathrm{a}\end{array}$ & $\begin{array}{c}20.96 \pm 1.36 \\
\mathrm{~d}\end{array}$ & $\begin{array}{c}15.40 \pm 0.46 \\
\mathrm{~b}\end{array}$ & $13.55 \pm 1.78$ \\
\hline 10 & $89.00 \pm 0.25 \mathrm{ab}$ & $\begin{array}{c}36.53 \pm 1.22 \\
\mathrm{e}\end{array}$ & $\begin{array}{c}6.75 \pm 0.22 \\
\text { bc }\end{array}$ & $\begin{array}{c}2.09 \pm 0.77 \\
\mathrm{a}\end{array}$ & $\begin{array}{c}22.76 \pm 2.48 \\
\mathrm{a}\end{array}$ & $\begin{array}{c}16.52 \pm 0.46 \\
\mathrm{a}\end{array}$ & $13.94 \pm 0.33$ \\
\hline 20 & $86.32 \pm 1.41 \mathrm{~d}$ & $\begin{array}{c}37.84 \pm 3.76 \\
\mathrm{c}\end{array}$ & $\begin{array}{c}8.01 \pm 0.19 \\
a b\end{array}$ & $\begin{array}{c}2.04 \pm 0.06 \\
\mathrm{a}\end{array}$ & $\begin{array}{c}22.15 \pm 0.57 \\
b\end{array}$ & $\begin{array}{c}17.16 \pm 0.18 \\
\mathrm{a}\end{array}$ & $13.80 \pm 0.45$ \\
\hline 30 & $86.65 \pm 0.33 \mathrm{~d}$ & $\begin{array}{c}40.56 \pm 3.36 \\
\mathrm{a}\end{array}$ & $\begin{array}{c}9.09 \pm 0.16 \\
\mathrm{a}\end{array}$ & $\begin{array}{c}1.99 \pm 1.34 \\
\mathrm{a}\end{array}$ & $\begin{array}{c}20.63 \pm 4.82 \\
\mathrm{~d}\end{array}$ & $\begin{array}{c}17.10 \pm 0.32 \\
\mathrm{a}\end{array}$ & $14.05 \pm 1.47$ \\
\hline 40 & $87.88 \pm 0.42 \mathrm{bc}$ & $\begin{array}{c}37.41 \pm 1.89 \\
\mathrm{~d}\end{array}$ & $\begin{array}{c}9.60 \pm 0.10 \\
\mathrm{a}\end{array}$ & $\begin{array}{c}2.08 \pm 1.15 \\
\mathrm{a}\end{array}$ & $\begin{array}{c}21.63 \pm 3.19 \\
\mathrm{c}\end{array}$ & $\begin{array}{c}17.00 \pm 0.34 \\
\mathrm{a}\end{array}$ & $13.75 \pm 1.45$ \\
\hline 50 & $87.01 \pm 0.28 \mathrm{~cd}$ & $\begin{array}{c}38.64 \pm 1.24 \\
\text { b }\end{array}$ & $\begin{array}{c}8.18 \pm 0.68 \\
a b\end{array}$ & $\begin{array}{c}1.94 \pm 0.14 \\
\mathrm{a}\end{array}$ & $\begin{array}{c}19.77 \pm 1.02 \\
\mathrm{e}\end{array}$ & $\begin{array}{c}16.60 \pm 0.48 \\
\mathrm{a}\end{array}$ & $13.48 \pm 0.38$ \\
\hline
\end{tabular}

\subsection{Effect of Hawthorn Addition on Fruit Flavonoid Content and Antioxidant Capacity}

As can be seen from Table 5, the flavonoid content in Pleurotus ostreatus is relatively low, but flavonoids are a very good antioxidant active substance. Long-term consumption of flavonoid-rich foods has the effect of delaying aging. The lower the IC50 value, the stronger the antioxidant activity of the alcohol extract of Pleurotus ostreatus. The higher the content of hawthorn seeds in the culture medium, the higher the flavonoid content of the fruit body of Pleurotus ostreatus and the stronger its antioxidant capacity. 
Table 5 Effect of different media on flavonoid content and antioxidant capacity of fruiting body

\begin{tabular}{cccc}
\hline $\begin{array}{c}\text { Added amount of } \\
\text { hawthorn seeds }(\%)\end{array}$ & $\begin{array}{c}\text { Flavonoid content } \\
(\%)\end{array}$ & $\begin{array}{c}\text { Dpph clearance } \\
\text { IC50 }(\mathrm{g} / \mathrm{L})\end{array}$ & $\begin{array}{c}\text { Hydroxylradical } \\
\text { scavenging rate }(\mathrm{g} / \mathrm{L})\end{array}$ \\
\hline 0 & $0.324 \pm 0.008 \mathrm{a}$ & $1.429 \pm 0.015 \mathrm{a}$ & $0.262 \pm 0.020 \mathrm{a}$ \\
10 & $0.340 \pm 0.002 \mathrm{a}$ & $1.299 \pm 0.035 \mathrm{~b}$ & $0.224 \pm 0.008 \mathrm{~b}$ \\
20 & $0.355 \pm 0.013 \mathrm{a}$ & $1.237 \pm 0.048 \mathrm{c}$ & $0.201 \pm 0.004 \mathrm{c}$ \\
30 & $0.358 \pm 0.021 \mathrm{a}$ & $1.193 \pm 0.011 \mathrm{~cd}$ & $0.157 \pm 0.006 \mathrm{~d}$ \\
40 & $0.359 \pm 0.039 \mathrm{a}$ & $1.099 \pm 0.025 \mathrm{e}$ & $0.121 \pm 0.002 \mathrm{e}$ \\
50 & $0.361 \pm 0.093 \mathrm{a}$ & $1.162 \pm 0.010 \mathrm{~d}$ & $0.100 \pm 0.005 \mathrm{f}$ \\
\hline
\end{tabular}

4. Wang Lei, Li Xianyu, Zhu Chuanhe. (2015)

\section{Conclusions}

Hawthorn seeds can be used to culture mushrooms.

Hawthorn Seed in Cultivation of Pleurotus ostreatus, and the bag filling time and harvest time of Pleurotus ostreatus can be shorten by adding hawthorn seeds to the culture medium. The biological efficiency of Pleurotus ostreatus can be improved through adding $30 \%$ hawthorn seeds. After adding the hawthorn seeds, the content of crude fiber increased, the content of total sugar, reducing sugar, and water decrease. The content of flavonoids and antioxidant activity in the fruit body of Pleurotus ostreatus increased with the addition of hawthorn seeds.

\section{Acknowledgments}

Fund Program: This research was financially supported by grants from "Double Tops" Program (SYT2017XTTD04), Shandong province key research and development plan (2017GNC10117, 2019GNC106023) , Shandong province agricultural major application technology innovation project and Shandong province science and technology plan projects(J14LF11). The first two authors contribute equally to this research

\section{References}

1. Xu Hongbo, Tang Zhishu, Liu Aoxin, He Xinyue, Song Mengya, Song Zhongxing, Lei Zhi'an, Wu Mingbin, Lu Shihai, Ren Zhenli, Su Xiaotao. (2018) Research Progress on Nuclear Chemical Composition and Pharmacological Activity of Hawthorn. J. Chinese Traditional Patent Medicine, 2018,40 ( 03): 674-680.

2. $\mathrm{Hu} \mathrm{Yu}$, Zhou Guangming, Luo Qinghong, Li Youlin. (2020) Simultaneous determination of nine phenolic acids and flavonoids in hawthorn by micellar extraction-cloud point pre-enrichment-high performance liquid chromatography. J /OL. China Traditional Chinese Medicine Information Magazine: 1-7.

3. Niu Zhenzhen, Zhao Xinling, Guo Yaoyao, Gong Yanling, Jin Hong. (2019) Optimization of Extraction Process and Fat Reducing Activity of Hawthorn Kernel Total Phenolic Acid by Response Surface Methodology. J. Journal of Qingdao University of Science and Technology (Natural Science), 2019, 40 (04): 38-45 + 53.
Study on technology of preparing activated carbon of hawthorn seed powder by phosphoric acid method. J. Food Research and Development, 2015, 36 (11): 85-89.

5. Huang Xiao-Xiao,Xu Yang,Bai Ming,Zhou Le,Song Shao-Jiang,Wang Xiao-Bo. (2017) Lignans from the seeds of Chinese hawthorn (Crataegus pinnatifida var. major N.E.Br.) against $\beta$-amyloid aggregation. J. Natural product research,2017.

6. Yang Qiaozhe. (2019) Cultivation technology of Pleurotus ostreatus. J. Modern Rural Science and Technology, 2019 (06): 27-28.

7. Lu Huan, Xu Ning, Wang Chunhui, Feng Liguo, Deng Zhaoli, Xia Yiliang. (2019) Effect of different nutritional conditions on the growth of Mycelia edodes. J. Jiangsu Agricultural Sciences, 2019, 47 (19): 113-117.

8. Feng Yan, Zhang Fang. (2019) Effect of Chinese medicine residue content on the yield and quality of Pleurotus ostreatus. J. Agricultural Development and Equipment, 2019 (10): 120-121.

9. Lei Yating, Chen Min, Liu Xinyi, Li Jing, Liu Bin, Lin Zhanyu. (2019) Effects of Fresh Giant Mycelium on the Physical Index and Nutritional Composition of Pleurotus ostreatus Fruit Body. J. China Edible Fungi, 2019, 38 (11): 61-68.

10. Zhang Ling, Shi Caiwen, Xiao Kaijun, Li Chunhai, Mo Junquan, Zhang Zhong, Shi Yuyu. (2019) Improvement and application evaluation of the determination of tilapia-derived collagen peptides by the biuret method. J. Food Science, 2019,40 ( 20): 234-240.

11. Niu Xiaojing, Chen Tianchao, Lu Jing, Shi Junhan, Ma Yanjiang. (2019) Determination of reducing sugar content in Huaijiao. J. Information on Traditional Chinese Medicine, 2019, 36 (06): 18-21.

12. Kwaw E., Ma Y., Tchabo W., Apaliya M. T., Wu M., Sackey A. S., Tahir H. E. (2018) Effect of lactorbacillus strains on phenolic profile, color attributes and antioxidant activities of lactic-acid-fermented mulberry juice. J. Food Chemistry, 2018, 250: 148-154.

13. Huang Yan. (2019) Effect of lactic acid bacteria fermentation on hawthorn pulp quality. D. Shandong Agricultural University, 2019. 